\title{
Intravenous liposomal benznidazole as trypanocidal agent: increasing drug delivery to liver is not enough
}

\author{
M.J. Morilla ${ }^{\text {a }}$, J.A. Montanari ${ }^{\text {a }}$, M.J. Prieto ${ }^{\text {a }}$, M.O. Lopez ${ }^{\text {a }}$, \\ P.B. Petray ${ }^{b}$, E.L. Romero ${ }^{\mathrm{a}, *}$ \\ ${ }^{a}$ Laboratorio de Diseño de Transportadores de Drogas, Universidad Nacional de Quilmes, \\ Roque Saenz Peña 180, Bernal, B1876BXD Buenos Aires, Argentina \\ ${ }^{\mathrm{b}}$ Laboratorio de Virología, Hospital de Niños Dr. R. Gutierrez, Gallo 1330, C1425EFD Buenos Aires, Argentina
}

Received 24 October 2003; received in revised form 16 March 2004; accepted 16 March 2004

Available online 25 May 2004

\begin{abstract}
With the aim of investigating if delivery of benznidazole (BNZ) to liver could be increased by incorporating the drug in multilamellar liposomes, single bolus of free BNZ or liposomal BNZ formulations (MLV-BNZ) composed of HSPC:DSPG:Chol 2:1:2 $(\mathrm{mol} / \mathrm{mol} / \mathrm{mol})$ at $0.7 \%(\mathrm{w} / \mathrm{w})$ drug/total lipid ratio, were injected by intramuscular (i.m.), subcutaneous (s.c.) and intravenous (i.v.) routes, at $0.2 \mathrm{mg} \mathrm{BNZ/kg}$, in rats. The resulting blood concentrations were followed along $9 \mathrm{~h}$ post-injection (p.i.) and drug accumulation in liver was determined after 4 and $9 \mathrm{~h}$ p.i. Only upon i.v. injection of MLV-BNZ, a threefold higher BNZ accumulation in liver was obtained, together with blood BNZ concentrations of $1.1 \mu \mathrm{g} / \mathrm{ml}$ ( $30 \%$ lower than the blood BNZ concentration achieved upon i.v. administration of free drug) occurred $4 \mathrm{~h}$ p.i. However, such increased liver uptake of BNZ, raised twice a week had no effect on parasitaemia levels of mice infected with the RA strain of Trypanosoma cruzi. Our results indicate that the relationship between increased selectivity for an infected tissue and therapeutic effect is not always straightforward, at least for the MLV-BNZ regimen used in the present study.
\end{abstract}

(C) 2004 Elsevier B.V. All rights reserved.

Keywords: Mutilamellar liposomes; Benznidazole

\section{Introduction}

Chagas' disease is endemic in several Latin American countries affecting 16-18 million people, with more than 100 million exposed to the risk of infection (WHO, 1997). It is caused by the hemoflagellate protozoan Trypanosoma cruzi, that reach the human blood stream after the bite and deposition of the vector insects (hematophagous triatomine

\footnotetext{
* Corresponding author. Tel.: +54-11-43657100; fax: +54-11-43657132.

E-mail address: elromero@unq.edu.ar (E.L. Romero).
}

bugs). In spite of the epidemiological importance of this disease, currently the only available therapeutic agent is the 2-nitroimidazol, benznidazole (BNZ) ( $N$-benzyl-2-nitro-1-imidazole-acetamide). BNZ is effective in the acute phase, in recent chronic infection (children under 12 years old) and congenital infection, but have little or no activity on the chronic phase (Coura and de Castro, 2002). Furthermore, severe side effects have been reported during its clinical use including polyneuritis, lymphadenopathy, dermatitis and depression of bone marrow (Cançado, 2002). As a consequence of these adverse reactions, frequently treatments have to be discontinued (Docampo and 
Moreno, 1985; Castro and Diaz de Toranzo, 1988). In spite of the lacking information about long-term treatments in humans, experimental evidence on its severe mutagenic, carcinogenic and reproductive toxic effects have been reported (Castro, 2000). Moreover, in growing number of reactivation forms after immunosupression due to AIDS or organ transplantation, consensus on BNZ use is still absent (Bocchi et al., 1998; Andrade et al., 2003).

Selective tissue targeting is absent for BNZ, since upon intestinal absorption BNZ binds to plasma proteins, red blood cells and distributes in many tissues (Barclay et al., 1978; De Toranzo et al., 1986). The controversial clinical evolution of BNZ-based therapies (meaning that studies by PCR amplification showed that the use of BNZ did not lead to a parasitological cure in chronic human treatments) (Braga et al., 2000) and not convincing results on BNZ capability to eradicate intracellular amastigotes (in vivo, BNZ fast and efficiently eliminates circulating parasites (trypomastigote forms), but its activity is considerably lower against the chronic form of the disease, where only amastigotes are present, in spite of the in vitro effectivity of BNZ to eliminate intracellular stages (Coura and de Castro, 2002). High doses of BNZ have to be taken in order to reach therapeutic blood levels against circulating forms, and probably the absence of selectivity for infected tissues makes difficult for the circulating drug to get inside the cell cytoplasm of the few infected tissue types in amounts enough to kill amastigotes. Hence, an increase of selectivity for those infected tissues, mediated by a mechanism that facilitate the massive delivery of drug inside the infected cells, should improve the results of the current therapy, specially against the intracellular forms.

With the aim of investigating if BNZ selectivity for hepatic tissue (one of the main tissue types colonized by $T$. cruzi) could be increased by its incorporation in a liposomal carrier, we have previously designed and in vitro assayed the pharmacological performance of BNZ encapsulated in multilamellar liposomes (MLV-BNZ) (Morilla et al., 2002). In the present work, we determined BNZ biodistribution and pharmacokinetics after parenteral administration of a single bolus of MLV-BNZ in healthy rats, and discuss the reasons of the lack of efficacy of this approach to reduce parasitaemia in an acute model of Chagas's disease.

\section{Materials and methods}

\subsection{Chemicals}

BNZ (purity: 99.85\%) was supplied by Roche Argentina (RO-07-1051/000). Hydrogenated soybean phosphatidylcholine (HSPC) and distearoyl-phosphatidylglycerol (DSPG) were from Northern Lipids (Vancouver, Canada). Dioleoyl-phosphatidylethanolamine (DOPE) was obtained from Avanti Polar-Lipids (Alabama, USA). Cholesterol (Chol) and cholesteryl hemisuccinate (CHEMS) were purchased by Sigma (St. Louis, USA). Dimethyl sulfoxide (DMSO) and acetonitrile (ACN) were of HPLC-quality (Carlo Erba Reagenti). Tris, trichloroacetic acid (TCA), $\mathrm{Cl}_{3} \mathrm{CH}$ and $\mathrm{CH}_{3} \mathrm{OH}$ were analysis grade from Anedra, Argentina. The $\mathrm{pH}$-sensitive fluorophore 8-hydroxypyrene-1,3,6-trisulfonate (HPTS) and the quencher $p$-xylene-bispyridinium bromide (DPX) were purchased from Molecular Probes (Eugene, OR).

\subsection{Liposomal preparation}

Briefly, MLV-BNZ composed of HSPC:DSPG:Chol $2: 1: 2(\mathrm{~mol} / \mathrm{mol} / \mathrm{mol})$ were prepared as previously described (Morilla et al., 2002), by mixing lipids from $\mathrm{Cl}_{3} \mathrm{CH}: \mathrm{CH}_{3} \mathrm{OH}(9: 1, \mathrm{v} / \mathrm{v})$ solution and BNZ in DMSO solution at $5: 100(\mathrm{~mol} / \mathrm{mol})$ drug to lipid ratio. The lipid-BNZ mixture was rotary evaporated at $50{ }^{\circ} \mathrm{C}$ in round bottom flasks until organic solvent elimination. The resulting film was flushed with $\mathrm{N}_{2}$, and suspended in $500 \mu \mathrm{l}$ of $10 \mathrm{mM}$ Tris-HCl buffer ( $\mathrm{pH}$ 7.4) up to a final concentration of around $20-30 \mu \mathrm{mol} / \mathrm{ml}$ total lipids. The free BNZ was eliminated by one step of centrifugation and the liposomal pellet was resuspended in Tris- $\mathrm{HCl}$ (pH 7.4).

\subsection{Physical characterization of liposomes}

Mean particle size was determined by dynamic light scattering at $25^{\circ} \mathrm{C}$ with a Nicomp 380 submicron particle sizer. The drug/total lipid ratio (D/L) $(\% \mathrm{w} / \mathrm{w})$ was determined before liposomal injection by lipid and BNZ quantitation. Lipid concentration was determined by a colorimetric phosphate micro assay (Bötcher et al., 1961) and encapsulated BNZ was determined after complete disruption of one 
volume of liposomal sample in 10 volumes of DMSO by reverse-phase HPLC (Morilla et al., 2003).

\subsection{Endocytosis and intracellular fate of liposomes follow by fluorescent microscopy}

MLV-BNZ were prepared as stated in Section 2.2 excepting that $35 \mathrm{mM}$ HPTS and $50 \mathrm{mM}$ DPX were added to the $10 \mathrm{mM}$ Tris- $\mathrm{HCl}$ buffer (pH 7.4). The free HPTS and DPX were eliminated by one step of centrifugation, the liposomal pellet was re-suspended in isotonic Tris- $\mathrm{HCl}$ buffer $(\mathrm{pH} 7.4)$ and incubated for different time points $(10,20,30$ and $40 \mathrm{~min})$ with the murine macrophage-like cell line J774; emission of the HPTS was monitored by fluorescence microscopy. Cells were previously cultured in RPMI medium containing $10 \%$ fetal calf serum. On the sixth or seventh day of culture, cells were replated and culture on coverslips in 24-multiwell dishes to be used the following day. As a positive control of cytosolic delivery, $\mathrm{pH}$-sensitive liposomes (which inner content is released from endo-lysosomal system, upon membrane phase transition induced by low $\mathrm{pH}$ ) were also incubated with $\mathrm{J} 774$ cells. pH-sensitive liposomes composed of DOPE/CHEMS (6:4, $\mathrm{mol} / \mathrm{mol}$ ) were prepared according to Daleke et al. (1990).

\subsection{Parenteral administration of $M L V-B N Z$}

Wistar rats (180-250 g body weight) received a single dose of $0.2 \mathrm{mg} / \mathrm{kg}$ of bulk BNZ (dissolved in isotonic Tris- $\mathrm{HCl}$ buffer, $\mathrm{pH}$ 7.4) or liposomal BNZ intravenously (i.v., via the lateral tail vein), intramuscularly (i.m., quadriceps) or subcutaneously (s.c., dorsal midline). The injection volume did not exceed $0.4 \mathrm{ml}$. Animals were divided into two subgroups for sample collection ( $n=3$ per subgroup). The first subgroup was bled at $0.5,1,2$ and $3 \mathrm{~h}$ and sacrificed at $4 \mathrm{~h}$. The second subgroup was bled at 5, 6, 7 and $8 \mathrm{~h}$ and sacrificed at $9 \mathrm{~h}$. Blood samples were collected from the retroorbital sinus on tubes containing sodium citrate. Immediately after sacrifice a final blood sample, liver, spleen, lungs, heart, kidney and the tissue surrounding the sites of injection were collected, washed, weighed and stored at $-80^{\circ} \mathrm{C}$. Additionally, parathymic, mandibular, mesenteric, axillary and inguinal lymph nodes were excised and weighed. Four extra animals were sacrificed 1 and $2 \mathrm{~h}$ after single i.v. injection of free or liposomal BNZ to measure the liver accumulation at that time points.

BNZ was extracted from rat tissues and quantified as previously described (Morilla et al., 2003) by a liquid-liquid extraction followed by HPLC separation and UV detection. Blood was extracted by the addition of $400 \mu \mathrm{l} \mathrm{ACN-DMSO}(1: 1, \mathrm{v} / \mathrm{v})$ to $200 \mu \mathrm{l}$ of sample, and incubated at $4{ }^{\circ} \mathrm{C}$ for $30 \mathrm{~min}$ in $1.5 \mathrm{ml}$ polypropylene tubes. After $20 \mathrm{~min}$ of centrifugation at $6000 \times g$, supernatants were transferred to fresh tubes, incubated $15 \mathrm{~min}$ at $-12^{\circ} \mathrm{C}$ with $100 \mu \mathrm{l}$ of TCA solution $10 \%(\mathrm{w} / \mathrm{v})$ and centrifuged $10 \mathrm{~min}$ at $10,000 \times \mathrm{g}$. Finally, $20 \mu \mathrm{l}$ from each supernatant was injected to the column. Liver, spleen, kidney, heart and lungs were washed with Tris- $\mathrm{HCl}$ buffer in order to remove the blood, minced in small pieces and stored at $-80^{\circ} \mathrm{C}$. A portion of each tissue (150-200 mg), including the sites of injection and the lymph nodes, was thawed and minced with $100 \mu \mathrm{l}$ of deionized water. The tissue homogenization/extraction of BNZ was done by the addition of ACN-DMSO (1:1, v/v) at 2:1 (extraction solvent:tissue, w/w) ratio. The process was completed following the same steps as described for blood and $20 \mu \mathrm{l}$ from each supernatant was injected to the column. Quantitation of BNZ in tissues was based on the peak area-concentration response of the HPLC calibration curves, performed on Beckman System Gold with a Programmable Solvent Module 125 and a Programmable Detector Module 166. The wavelength was set at $324 \mathrm{~nm}$ with a response time of $1 \mathrm{~s}$. The analytical column was a reverse phase Kromasil C18 $(25 \mathrm{~cm} \times 0.4 \mathrm{~cm}$ i.d., $100 \AA$, $5 \mu \mathrm{m}$ particle size $)$. The mobile phase used was acetonitrile-water (40:60, v/v), degassed by vacuum. Elution was performed isocratically at a flow rate of $0.9 \mathrm{ml} / \mathrm{min}$.

\subsection{Infected animals}

Female 4- to 6-week-old Balb/c mice (average body weight $25-30 \mathrm{~g}$ ) were infected intraperitoneally with $50 \mathrm{~T}$. cruzi trypomastigotes/mouse. The pantropic/reticulotropic RA strain was used in this study, which is efficiently internalized by macrophages (Celentano and Gonzalez Cappa, 1993). The animals were separated into four groups and treatments started on the fifth day post-infection consisted of 2 days a week i.v. injection of $0.4 \mathrm{mg}$ 
BNZ/kg ( 2 and 3 days between injections). Group 1: received $0.1 \mathrm{ml}$ of free $\mathrm{BNZ}$ dissolved in isotonic solution. Group 2: received $0.1 \mathrm{ml}$ of MLV-BNZ; Group 3: received $0.1 \mathrm{ml}$ of empty liposomes (MLV), given at the same total lipid dose than Group 2 (60 $\mathrm{mg}$ of lipids $/ \mathrm{kg}$ ); Group 4: received $0.1 \mathrm{ml}$ of isotonic buffer. Parasitaemia was monitored by daily counting of the number of trypomastigotes per $5 \mu l$ of fresh blood (Pizzi, 1957). Statistical analyses were carried out with the Prisma 3.0 Software

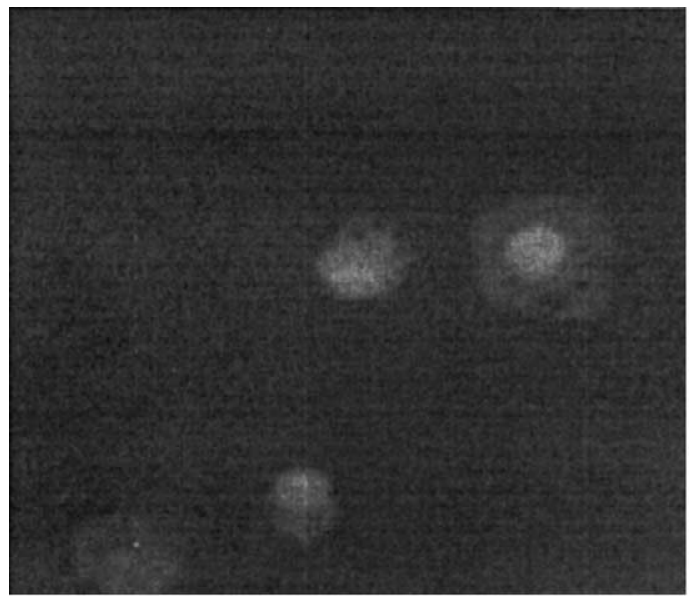

(a)

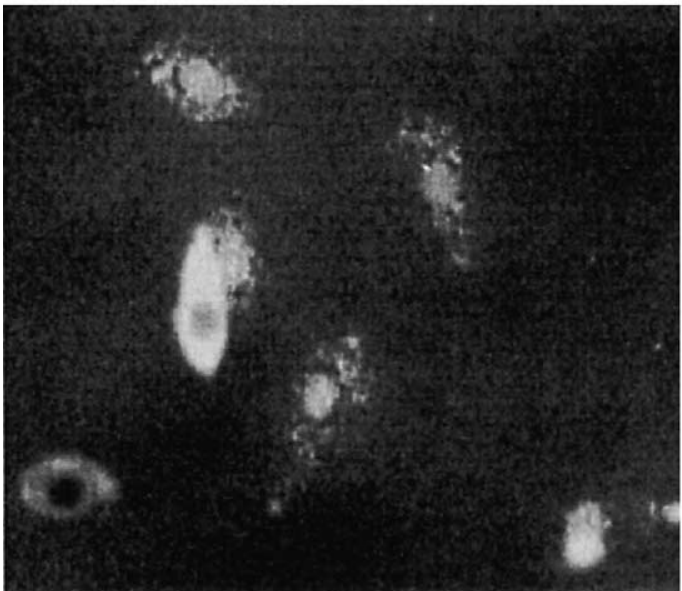

(b)
(GraphPad, San Diego, CA). Mann-Whitney test and Fisher exact probability test were conducted for the analyses of parasitaemia and survival curves, respectively. Differences were considered statistically significant when $P<0.05$. Note that the administration of equal doses of liposomes to rodents renders comparable biodistribution and is independent of the specie (Barenholz, 1998; Harashima et al., 1996; Lasic, 1993; Shimizy et al., 1998; Wu et al., 1998).

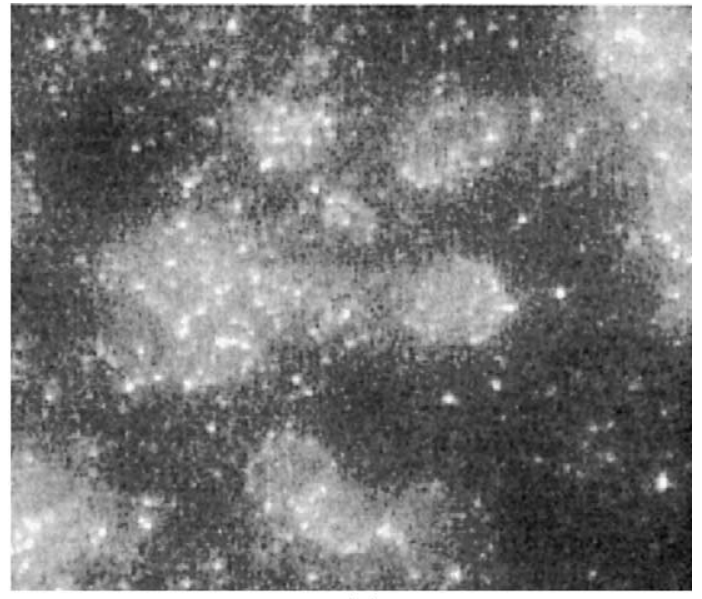

(c)

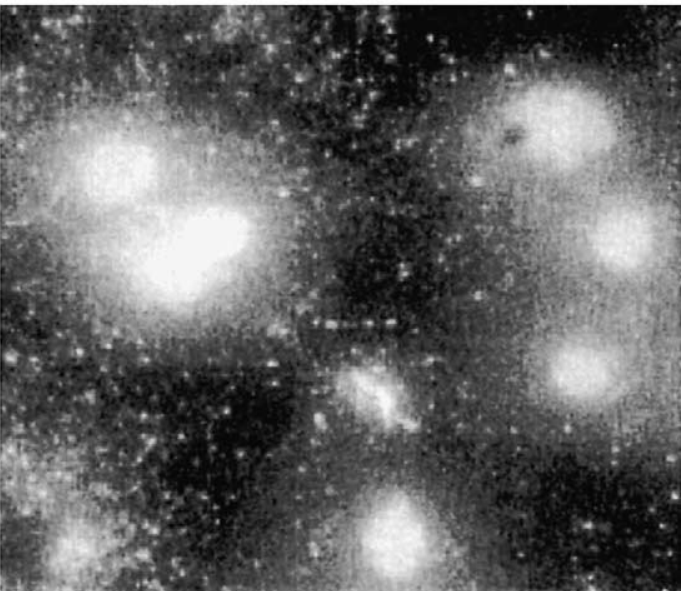

(d)

Fig. 1. Fluorescence of J774 cells incubated with liposomes loaded with HPTS. Upon incubation at $37^{\circ} \mathrm{C}$ the liposomal suspension was removed, the cells were four times washed and the coverslip was mounted on the microscope. The emission at $510 \mathrm{~nm}$ resulted from excitation with blue filter $(450-490 \mathrm{~nm})$ was seen with an Olympus BH2-RFGA fluorescence microscope. (a) and (b) Fluorescence observed 20 and $40 \mathrm{~min}$ after incubation with MLV-BNZ, respectively. (c) and (d) Fluorescence of J774 cells incubated 5 and 15 min with pH-sensitive liposomes loaded with HPTS. 


\section{Results}

\subsection{Physical characterization of liposomes}

The mean diameter of the multilamellar vesicles was $2 \pm 0.5 \mu \mathrm{m}$. The concentration of the resulting liposomal suspensions was $15.5 \pm 1.2 \mathrm{mg} / \mathrm{ml}$ at a $0.7 \%$ $\mathrm{D} / \mathrm{L}$ ratio, rendering a $33 \%$ efficiency of encapsulation.

\subsection{Endocytosis and intracellular fate of liposomes followed by fluorescent microscopy}

The object of this assay was assessing the uptake and intracellular pathway of MLV-BNZ inside phagocytic cells. To that aim, MLV-BNZ containing the $\mathrm{pH}$-sensitive fluorescent dye HPTS within the aqueous compartments were incubated with $\mathrm{J} 774$ cells. Our results showed that uptake process should take longer than $20 \mathrm{~min}$, due to the absence of fluorescence during that period (Fig. 1a). Fluorescence, as defined points on the cell surface appeared after $30 \mathrm{~min}$ of incubation; the amount of fluorescent points increased towards $40 \mathrm{~min}$ of incubation and remained as defined pale points with neither diffusion nor increased brightness up to $90 \mathrm{~min}$ of observation. Fig. 1b shows the fluorescence of macrophage incubated during $40 \mathrm{~min}$ with MLV-BNZ-HPTS, indicating complete internalization of liposomal particles, and confinement inside the endo-lysosomal system, without delivery of HPTS to the cytosol. In contrast, after 5 min of incubation with $\mathrm{pH}$-sensitive liposomes a lot of fluorescent point were observed on the cell surface (Fig. 1c) and bright homogeneous HPTS fluorescence in cytosol was seen in Fig. 1d after 15 min.

\subsection{Parenteral administration of $M L V-B N Z$}

\subsubsection{Blood concentration profiles of free and $M L V-B N Z$ according to different routes of administration}

Fig. 2a depicts the BNZ concentration in blood upon a single parenteral administration of free BNZ. Blood BNZ profiles corresponding to i.m. and s.c. routes followed the same trend, but the i.m. levels were substantially higher than the s.c. levels over the first $4 \mathrm{~h}$. During the first $4 \mathrm{~h}$, blood BNZ was sustained in the order of $1.2-1.5 \mu \mathrm{g} / \mathrm{ml}$ and from that time point on it dropped under the lower limit of quantification (LLQ)
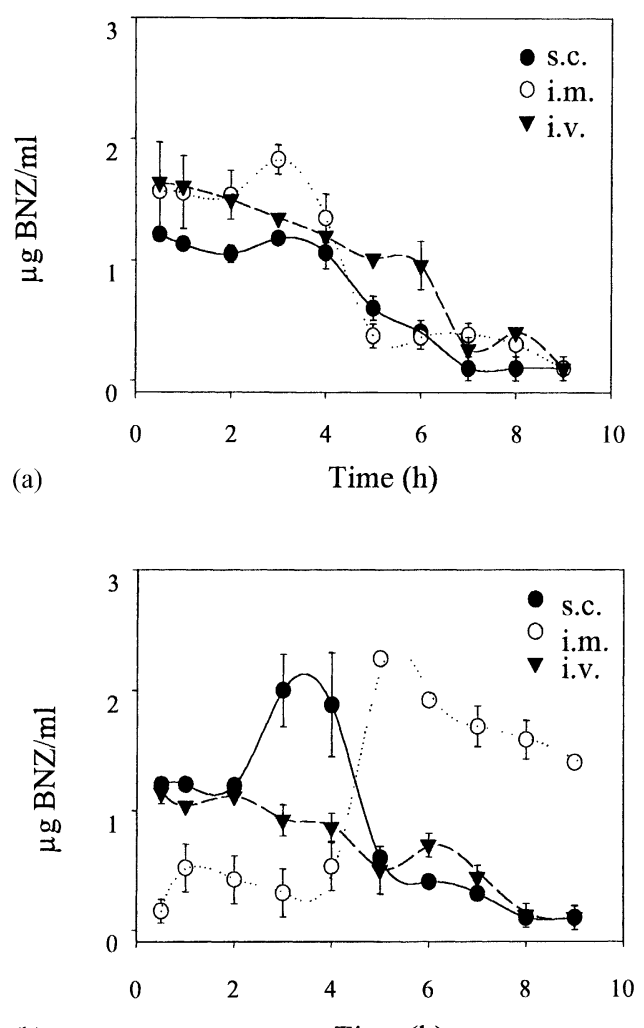

(b)

Fig. 2. (a) Concentration vs. time profiles in blood after i.v., i.m. and s.c. administration of free BNZ as an isotonic solution at a single dose of $0.2 \mathrm{mg} / \mathrm{kg}$. Each point plots the mean level of three rats at time point \pm standard error (S.E.M.). (b) Concentration vs. time profiles in blood after i.v., i.m. and s.c. administration of liposomal BNZ (MLV-BNZ) at a single dose of $0.2 \mathrm{mg} / \mathrm{kg}$. Each point plots the mean level of three rats at time point \pm standard error (S.E.M.).

$(0.6 \mu \mathrm{g} / \mathrm{ml})$. Conversely, blood BNZ upon i.v. injection started at 1.6, to fall below $0.6 \mu \mathrm{g} / \mathrm{ml}$ from $6 \mathrm{~h} \mathrm{p}$.i.

Fig. 2b depicts the BNZ concentration in blood upon a single parenteral administration of MLV-BNZ. Blood BNZ profiles corresponding to i.m. and s.c. routes were not coincident. Upon s.c. administration blood BNZ raised from 1.2 to $2 \pm 0.3 \mu \mathrm{g} / \mathrm{ml}$ at 3-4h p.i.; from the $5 \mathrm{~h}$ p.i. on, it dropped under the LLQ. During the first $4 \mathrm{~h}$ upon i.m. administration, blood BNZ was under the LLQ, to raise up to $2.3 \pm 0.02 \mu \mathrm{g} / \mathrm{ml}$ at $5-6 \mathrm{~h}$ p.i., remaining around $1.4 \mu \mathrm{g} / \mathrm{ml}$ up to $9 \mathrm{~h}$ p.i. Blood BNZ upon i.v. injection was $1.1 \pm 0.03 \mu \mathrm{g} / \mathrm{ml}(30 \%$ lower than the maximal concentration achieved upon free BNZ i.v. 


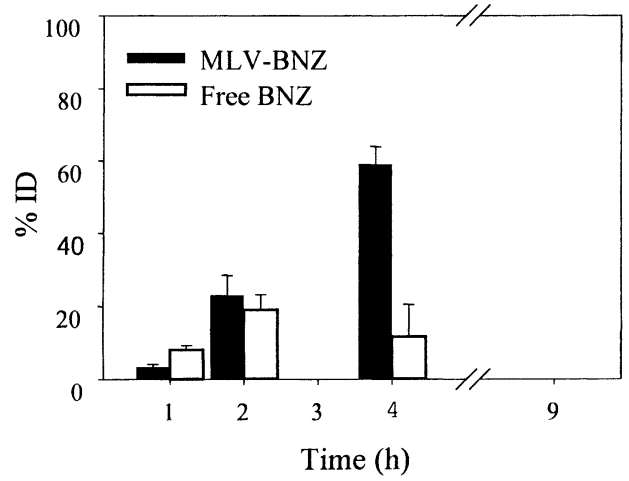

Fig. 3. Drug accumulation in liver after i.v. administration of free and liposomal BNZ. The values are expressed as percentage of injected dose (\%ID) normalized to a standard liver weight of $7 \mathrm{~g}$.

injection $1.6 \mu \mathrm{g} / \mathrm{ml}$ ), dropped to $0.8 \pm 0.01 \mu \mathrm{g} / \mathrm{ml}$ during the first $4 \mathrm{~h}$ and from there it dropped under the LLQ.

\subsubsection{Free and $M L V-B N Z$ in liver}

Upon i.m. and s.c. administration of free and liposomal BNZ the drug was non-detectable (n.d.) at 4 and $9 \mathrm{~h}$ p.i. in the surveyed organs (liver, spleen, lungs, heart and kidneys). Remnant drug in the site of injection and in the lymph nodes was also n.d.

Fig. 3 shows drug accumulation in liver after i.v. injection as a function of time. BNZ was n.d. in other organs than the liver. The amount of BNZ found in liver after the administration in the free form, increased up to $2 \mathrm{~h}$ p.i. and decreased toward the $4 \mathrm{~h}$ p.i. being n.d. at the end of the study ( $9 \mathrm{~h}$ p.i.). Liposomal BNZ showed maximal liver accumulation at $4 \mathrm{~h}$ p.i., to be n.d. at $9 \mathrm{~h}$ p.i. By comparing the two peaks in liver, the liposomal BNZ appeared $2 \mathrm{~h}$ later, and was threefold higher than the achieved with free BNZ. MLV-BNZ was also i.v. injected in multiple dosage of 2 days a week during 2 weeks and liver BNZ accumulation registered $4 \mathrm{~h}$ p.i. in the last dosage day, was not higher than that achieved with single dose (data not shown).

\subsection{Infected animals}

In Fig. 4 is shown the parasitaemia of the infected animals upon the different treatments. Both the group treated with MLV-BNZ and the group treated with

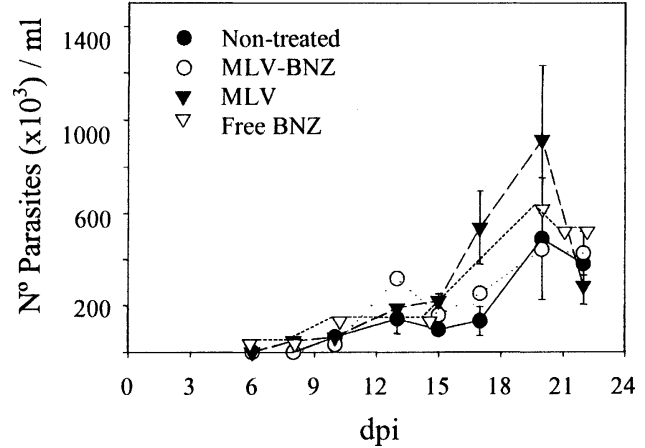

Fig. 4. Course of parasitaemia of RA T. cruzi strain infected mice for different treatments. dpi: days post-infection.

empty liposomes showed the same peak of parasitaemia in the 20th day post-infection (dpi) than the control (without treatment) group and the group that received BNZ as solution.

\section{Discussion}

Two quantities have to be defined before i.v. administration of liposome suspensions, in order to avoid toxic effects: the amount of lipid carrier $/ \mathrm{kg}$ and the bolus volume. Obviously, both depend on the lipid concentration of the original liposomal suspension, and are calculated on the bases of empirical data. In other words, the maximum mass of liposomal drug will be ruled by the $\mathrm{D} / \mathrm{L}$ ratio and lipid concentration of the liposomal suspension; that drug amount cannot be surpassed, because of potential appearance of harmful effects. The maximal liposomal lipid amount $/ \mathrm{kg}$ must not exceed the values over which a reticulo-endothelial system (RES) blockade is produced (Olson et al., 1982, reported a $\mathrm{LD}_{50}$ for a single i.v. injection of MLV (phosphatidylcholine/Choi) of $7.2 \mathrm{~g} / \mathrm{kg}$ ) whereas 0.5 and $0.2 \mathrm{ml}$ are the maximal recommended i.v. injection volume for rats and mice, respectively (Flecknell, 1987). Hence, for the present MLV-BNZ suspension (see Section 3.1), an injection volume of $0.4 \mathrm{ml}$ resulted in a safe dose of $30 \mathrm{mg}$ of lipids $/ \mathrm{kg}$ and determined a maximum BNZ dose of $0.2 \mathrm{mg} / \mathrm{kg}$ for rats. To get comparable data, in rats $0.4 \mathrm{ml}$ of free or liposomal BNZ was i.v., s.c. and i.m. injected whereas infected mice were injected with $0.1 \mathrm{ml}$ (a $0.4 \mathrm{mg} / \mathrm{kg}$ BNZ dose). 
Firstly, the assay described in Section 3.2 accounted for the existence of phagocytic uptake of liposomal particles loaded with BNZ. Since upon excitation at $440 \mathrm{~nm}$, punctual and pale emission indicates HPTS in acidic compartments (HPTS confined to endosomes/lysosomes), whereas homogeneously distributed strong emission indicates HPTS in a neutral compartment (cytosol) (Daleke et al., 1990; Straubinger et al., 1990), the assayed revealed the confinement of loaded hydrophilic marker inside the endo-lysosomal system. Therefore, for the small hydrophobic BNZ loaded in liposomes, it was expected that its permeation across the endosomal or lysosome membranes would only depend on its own chemical structure (Lloyd, 2000).

We injected single bolus of liposomal BNZ by three parenteral routes: i.m., s.c. and i.v., and examined the resulting BNZ blood concentration along the $9 \mathrm{~h}$ p.i. and BNZ biodistribution at 4 and $9 \mathrm{~h}$ p.i. First, we tested if an increased liver accumulation, as compared to that produced upon injecting free BNZ, could be achieved by injecting liposomal BNZ. Second, on increased BNZ liver accumulation, we tested its influence on the infection produced by the RA strain of $T$. cruzi in mice.

Neither by injecting single bolus (as free or MLV-BNZ) by the i.m. nor by the s.c. routes, it was possible to increase BNZ accumulation in liver above that achieved upon i.v. administration of free drug. The big mean size (above $100 \mathrm{~nm}$ ) of liposomes injected by i.m. or s.c. routes impairs the blood extravasation of the entire liposomal particle (Oussoren et al., 1997) and is expectable that solely free BNZ was released to circulation. The resulting peak of blood BNZ, first upon s.c. and $1 \mathrm{~h}$ later upon i.m. MLV-BNZ administration indicated a burst from a tissue liposomal depot. The burst effect was absent after i.m. or s.c. free BNZ administration. Previous data on free BNZ distribution (after oral or parenteral administration) indicate the absence of a selective tissue or cell uptake (De Toranzo et al., 1986). However, upon MLV-BNZ i.v. injection, a threefold higher (less than $5 \mathrm{~h}$ duration) BNZ accumulation in liver was produced. Remarkably, the existence of anatomical barriers $(150 \mathrm{~nm}$ size of endothelial fenestration) is known to impair the access of particulate material (like $2 \mu \mathrm{m}$ mean sized MLV-BNZ) to the hepatocytes (Brouwer et al., 1988). It is feasible then, that i.v. injected MLV-BNZ were mainly phagocytosed by Kupffer cells (KC), one of the main cell types colonized by the parasites used in this experiment and that an increased massive delivery of BNZ to this cell type (80-90\% all resident macrophages in the body) could be obtained (Kuiper et al., 1994). However, we also observed that such a transient higher liver BNZ accumulation raised twice a week (according to a 2 days a week dosage) had no effect on the parasitaemia levels of infected mice.

Our results indicated that for the MLV-BNZ regimen used in the present study on an acute infection produced by the RA strain of $T$. cruzi, the relationship between increased selectivity on infected liver and therapeutic effect, was not straightforward. Factors such as: chemical nature of trypanocide drug (intracellular pathway of MLV-BNZ in macrophages followed by fluorescence indicated that delivery of loaded BNZ to cytosol should exclusively depend on degree of BNZ permeation across the lysosomal membrane, which in turn relies on BNZ chemical structure); type of liposomal carrier ( $\mathrm{pH}$-sensitive unilamellar liposomes should allow massive delivery of drug to cytosol, but this type of carrier was unsuitable for BNZ loading); Parasitized tissue (RA strain infects hepatic macrophages but also spleen, nerve and muscle; non-phagocytic cells should be excluded from liposomal delivery); intracellular location (phago-lysosomes are easily targeted by phagocytosed liposomes, while targeting cytosolic amastigotes require further content from endo-lysosomes to the cytosol); and sustained versus transient dosage, all form a complex frame to be considered when deciding employing a controlled drug release strategy.

\section{Acknowledgements}

The authors are grateful to Dr. Bruno Maggio from CIQUIBIC, Facultad de Ciencias Químicas, Universidad Nacional de Cordoba, and to Cintia Smus for her technical assistance. Maria J. Morilla has got a post-graduate fellowship from the Comisión de Investigaciones Científicas (CIC) de la provincia de Buenos Aires, Argentina; Patricia Petray is member of the Researcher Career Programme from the Consejo Nacional de Investigaciones Cientificas y Técnicas, Argentina. This research was supported by a grant from the Universidad Nacional de Quilmes. 


\section{References}

Andrade, S.G., Mesquita, I.M., Jambeiro, J.F., Santos, I.F., Portella, R.S., 2003. Treatment with benznidazole in association with immunosuppressive drugs in mice chronically infected with Trypanosoma cruzi: investigation into the possible development of neoplasias. Rev. Soc. Bras. Med. Trop. 36, 441-447.

Barclay, C.A., Cerisola, J.A., Lugones, H.O., Ledesma, J., Lopez Silva, G., Mouzo, J., 1978. Aspectos farmacológicos y resultados terapéuticos del benznidazol en el tratamiento de la infección chagasica. Pres. Med. Argent. 65, 239-244.

Barenholz, Y., 1998. Section VII, Chapter 7.1. Design of liposomebased-drug carriers: from basic research to application as approved drugs. In: Lasic, D.D., Papahadjopoulos, D. (Eds.), Medical Applications of Liposomes. Elsevier, pp. 545-560.

Bocchi, E.A., Higuchi, M.L., Vieira, M.L., Stolf, N., Bellotti, G., Fiorelli, A., Uip, D., Jatene, A., Pileggi, F., 1998. Higher incidence of malignant neoplasms after heart transplantation for treatment of chronic Chagas' heart disease. Heart Lung Transplant. 17, 399-405.

Bötcher, C.J.F., van Gent, C.M., Pries, C., 1961. A rapid and sensitive sub-micro phosphorus determination. Anal. Chim. Acta 24, 203-204.

Braga, M.S., Lauria-Pires, L., Arganaraz, E.R., Nascimento, R.J., Teixeira, A.R.L., 2000. Persistent infections in chronic Chagas' disease patients treated with anti-Trypanosoma cruzi nitroderivatives. Rev. Inst. Med. Trop. S. Paulo 42, 157-161.

Brouwer, A., Wisse, E., Knook, D.L., 1988. Sinusoidal endothelial cells and perinsinusoidal fat-storing cells. In: Arias, I.M., Boyer, J.L., Fausto, N., Jakoby, W.B., Schachter, D.A., Shafritz, D.A. (Eds.), The Liver: Biology and Pathobiology, 2nd ed. Raven Press, New York, pp. 665-682.

Cançado, J.R., 2002. Long term evaluation of etiological treatment of Chagas' disease with benznidazole. Rev. Inst. Med. Trop. S. Paulo 44, 29-37.

Castro, J.A., 2000. Contributions of toxicology to the problem of Chagas' disease (American Trypanosomiasis) - a year 2000 update. Biomed. Environ. Sci. 13, 271-279.

Castro, J.A., Diaz de Toranzo, E.G., 1988. Toxic effects of nifurtimox and benznidazole, two drugs used against American Trypanosomiasis (Chagas' disease). Biomed. Environ. Sci. 1, 19-33.

Celentano, A.M., Gonzalez Cappa, S.M., 1993. In vivo macrophage function in experimental infection with Trypanosoma cruzi subpopulations. Acta Tropica 55, 171-180.

Coura, J.R., de Castro, S.L., 2002. A critical review on Chagas disease chemotherapy. Mem. Inst. Oswaldo Cruz 97, 3-24.

Daleke, D.L., Hong, K., Papahadjopoulos, D., 1990. Endocytosis of liposomes by macrophages: binding, acidification and leakage of liposomes monitored by a new fluorescence assay. Biochim. Biophys. Acta 1024, 352-366.

De Toranzo, E.G.D., Masana, M., Castro, J.A., 1986. Distribucion del benznidazol administrado oralmente en los diferentes tejidos de ratas macho. Acta Bioquimica Clinica Latinoamericana XX, 61-64.
Docampo, R., Moreno, S.N., 1985. Biochemical toxicology of antiparasitic compounds used in the chemotherapy and chemoprophylaxis of American Trypanosomiasis (Chagas' disease). Rev. Biochem. Toxicol. 7, 159-204.

Flecknell, P.A., 1987. Laboratory Animal Anesthesia: An Introduction for Research Workers and Technicians. Academic Press, Florida.

Harashima, H., Komatsu, S., Kojima, S., Morioka, Y., Naito, M., Kiwada, H., 1996. Species difference in the disposition of liposomes among mice, rats and rabbits: allometric relationship and species dependent hepatic uptake mechanism. Pharmaceutic. Res. 13, 1049-1054.

Kuiper, J., Brouwer, A., Knook, D.L., van Berkel, T.J.C., 1994. Kupffer and sinusoidal endothelial cells. In: Arias, I.M., Boyer, J.L., Fausto, N., Jakoby, W.B., Schachter, D.A., Shafritz, D.A. (Eds.), The Liver: Biology and Pathobiology, 3rd ed. Raven Press, New York, pp. 791-818.

Lasic, D.D., 1993. Chapter 11: Liposomes as a drug delivery system, fate of liposomes in vivo. In: Lasic, D.D. (Ed.), Liposomes: From Physics to Application. Elsevier, pp. 280-321.

Lloyd, J.B., 2000. Lysosomal membrane permeability: implications for drug delivery. Adv. Drug Deliv. Rev. 41, 189-200.

Morilla, M.J., Benavidez, P., Lopez, M.O., Bakas, L., Romero, E.L., 2002. Development and in vitro characterisation of a benznidazole liposomal formulation. Int. J. Pharm. 249, 8999.

Morilla, M.J., Benavidez, P.E., Lopez, M.O., Romero, E.L., 2003. Liposomal benznidazole: a high performance liquid chromatographic determination for biodistribution studies. J. Chromatogr. Sci. 41, 405-409.

Olson, F., Mayhew, E., Marlow, D., Rustum, Y., Szoka, F., 1982. Characterization, toxicity and therapeutic efficacy of adriamycin encapsulated in liposomes. Eur. J. Cancer Clin. Oncol. 18, 167-176.

Oussoren, C., Zuidema, J., Crommelin, D.J.A., Storm, G., 1997. Lymphatic uptake and biodistribution of liposomes after subcutaneous injection. II. Influence of liposomal size, lipid composition and lipid dose. Biochim. Biophys. Acta 1328, 261-272.

Pizzi, T., 1957. Prensa Medica Universitaria Santiago de Chile, p. 38.

Shimizy, K., Qi, X.R., Maitani, Y., Yoshii, M., Kawano, K., Takayama, K., Nagai, T., 1998. Targeting of soybean-derived sterylglucoside liposomes to liver tumors in rat and mouse models. Biol. Pharm. Bull. 21, 741-746.

Straubinger, R.M., Papahadjopoulos, D., Hong, K., 1990. Endocytosis and intracellular fate of liposomes using pyranine as a probe. Biochemistry 29, 4929-4939.

World Health Organization (WHO), 1997. Chagas disease. Thirteenth programme report UNDP/TDR, Geneve.

Wu, J., Liu, P., Zhu, J.L., Maddukuri, S., Zern, M.A., 1998. Increased liver uptake of liposomes and improved targeting efficacy by labelling with asialofetuin in rodents. Hepatology 27, 772-778. 